DOI: $\underline{\text { https://doi.org/10.31933/jemsi.v2i5 }}$

Received: 16 April 2021, Revised: 15 Mei 2021, Publish: 4 Juli 2021

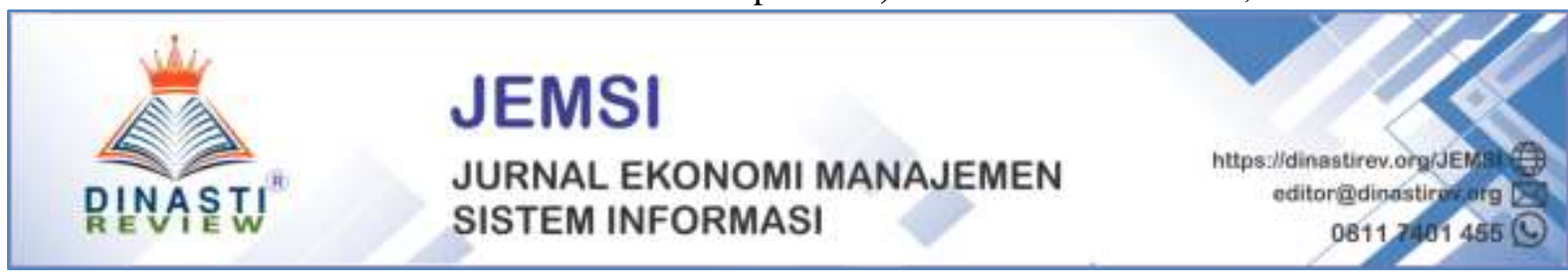

\title{
FAKTOR-FAKTOR YANG MEMPENGARUHI SWOT: STRATEGI PENGEMBANGAN SDM, STRATEGI BISNIS, DAN STRATEGI MSDM (SUATU KAJIAN STUDI LITERATUR MANAJEMEN SUMBERDAYA MANUSIA)
}

\section{Tuti Fitri Anggreani}

Mahasiswa Fakultas Magister Manajemen, Universitas Mercu Buana, tuttifitria@gmail.com

\begin{abstract}
Abstrak: Riset terdahulu atau riset yang relevan sangat penting dalam suatu riset atau artikel ilmiah. Riset terdahulu atau riset yang relevan berfungsi untuk memperkuat teori dan penomena hubungan atau pengaruh antar variable. Artikel ini mereview Faktor-faktor yang mempengaruhi SWOT, yaitu: Strategi Pengembangan SDM, Strategi Bisnis, dan Strategi MSDM suatu studi literatur Manajemen Sumberdaya Manusia. Hasil artikel literature review ini adalah: 1) Strategi Pengembangan SDM berpengaruh terhadap SWOT; 2) Strategi Bisnis berpengaruh terhadap SWOT; dan 3) Strategi MSDM berpengaruh terhadap SWOT.
\end{abstract}

Kata Kunci: SWOT, Strategi Pengembangan SDM, Strategi Bisnis, dan Strategi MSDM

\section{PENDAHULUAN}

\section{Latar Belakang Masalah}

Dalam suatu bisnis perusahaan di butuhkan strategi yang kuat untuk menghadapi kompetitor. Banyak strategi diantaranya; Strategi Bisnis, Strategi SDM, Strategi Pemasaran, dan Strategi Operasional. Peranan Sumber Daya Manusia (SDM) merupakan salah satu komponen penting dalam sebuah perusahaan. Sementara faktor sarana dan prasarana, sistem, fasilitas, asset serta bahan merupakan faktor pelengkap terhadap sumber daya manusia. Semua faktor pelengkap tersebut tidak akan berfungsi optimal jika tidak ada sumberdaya manusia sebagai penggerak, pemikir dan perencana untuk mencapai tujuan organisasi, baik itu di dalam institusi maupun perusahaan yang memiliki fungsi sebagai asset sehingga harus dilatih dan 
dikembangkan kemampuannya.

Suatu kekuatan tidak selalu menjadi sumber keunggulan kompetitif. Disisni perusahaan tidak cukup hanya memiliki satu keunggulan unuk memenangkan persaingan seperti halnya keuangan, teknologi, dan merk yang substansial. Namun diperlukan suatu formulasi strategi yang dapat dijadikan sumber keunggulan kompetitif. Secara ringkas analisis SWOT merupakan suatu pendekatan tradisional yang sudah lama digunakan oleh para pembuat strategi untuk melakukan analisis internal.

Proses pengambilan keputusan startegis perusahaan selalu berkaitan erat dengan pengembangan misi, visi, tujuan, strategi serta kebijakan perusahaan. Oleh karenanya perencanaan yang strategis sangat memerlukan analisa-analisa dari masing SWOT ini (kekuatan, kelemahan, peluang dan ancaman) di lingkungan perusahaan saat ini. Berdasarkan uraian di atas, maka dapat di katakan sumber daya manusia merupakan faktor utama dalam kemajuan sebuah perusahaan dan setiap perusahaan yang ingin berkembang harus mengembangkan sumber daya manusianya untuk memenuhi tujuan perusahaan.

\section{Rumusan Masalah}

Berdasarkan latar belakang akan di rumuskan masalah yang akan di bahas pada artikel literature review agar lebih focus pada kajian pustaka dan hasil serta pembahasan nanti, yaitu:

1) Apakah Strategi Pengembangan SDM memiliki hubungan dan berpengaruh terhadap SWOT?

2) Apakah Strategi Bisnis memiliki hubungan dan berpengaruh terhadap SWOT?

3) Apakah Strategi MSDM memiliki hubungan dan berpengaruh terhadap SWOT?

\section{KAJIAN PUSTAKA}

\section{Strategi Pengembangan SDM}

Strategi pengembangan SDM merupakan suatu perencanaan mengenai cara bagaimana kualitas SDM mampu berkembang ke arah yang lebih baik dan meningkat kemampuan kerjanya. Serta memiliki loyalitas yang baik terhadap perusahaan. Pengembangan SDM sangat dibutuhkan untuk kelangsungan sebuah perusahaan agar dapat berkembang secara lebih dinamis. Sebab 
SDM merupakan unsur yang paling penting di dalam sebuah perusahaan.

\section{Strategi Bisnis}

Strategi bisnis adalah kemampuan pengusaha/perusahaan dalam analisis lingkungan eksternal dan internal perusahaan, perumusan (formulasi) strategi, pelaksanaan (implementasi) rencanarencana yang dirancang untuk mencapai sasaran-sasaran perusahaan, serta melakukan evaluasi untuk mendapatkan umpan balik dalam merumuskan strategi yang akan datang. Variabel ini diukur dengan 3 dimensi yaitu: differentiation, low cost, dan focus strategy.

\section{Strategi MSDM}

Menurut Barry Cushway, MSDM didefinisikan sebagai rangkaian strategi, proses, dan aktifitas yang didesain untuk menunjang tujuan perusahaan dengan cara mengintegrasikan kebutuhan perusahaan dan individu (Barry, 2012: 5). Definisi yang diberikan oleh Barry ini jelas mengarahkan manajemen pada strateginya terhadap tujuan perusahaan. Akan tetapi, ini tidak berarti definisi ini tak dapat dipakai dalam ruang organisasi. Karena sesungguhnya sebuah perusahaan juga merupakan organisasi yang bergerak dalam hal finansial, salah satunya. Akan tetapi, ada hal yang perlu diperhatikan, bahwasannya manajemen sumber daya manusia (MSDM) berbeda dari manajemen personalia.

\section{Analisis SWOT}

Menurut Boseman dalam Wisnubrot (2013:162), analisis SWOT (SWOT analysis) adalah proses penarikan kekuatan, kelemahan, kesempatan dan ancaman dalam organisasi dan dunia bisnis dikenal sebagai penaksiran atau analisis SWOT.

Sedangkan Jogiyanto dalam Widharta (2013:6) menjelaskan bahwa analisis SWOT adalah semua organisasi memiliki kekuatan dan kelemahan dalam area fungsional bisnis. Tidak ada 
perusahaan yang sama kuatnya atau lemahnya dalam semua area bisnis. Kekuatan atau kelemahan internal, digabungkan dengan peluang dan ancaman dari eksternal dan pernyataan misi yang jelas, menjadi dasar untuk penetapan dengan maksud strategi. Tujuan dan strategi diterapkan dengan maksud memanfaatkan kekuatan internal dan mengatasi kelemahan.

Menurut salah satu pakar SWOT, Fredy Rangkuti, analisis SWOT adalah identifikasi berbagai faktor secara sistematis untuk merumuskan strategi perusahaan. Analisis ini didasarkan pada hubungan atau interaksi antara unsur internal, yaitu kekuatan dan kelemahan, terhadap unsurunsur eksternal yaitu peluang dan ancaman.

Analisis SWOT merupakan bentuk analisis situasi dan kondisi yang bersifat deskriptif (memberi gambaran). Analisis ini menempatkan situasi dan kondisi sebagai faktor masukan, kemudian dikelompokkan menurut kontribusinya masing-masing. Analisis SWOT adalah alat analisis yang ditujukan untuk menggambarkan situasi yang sedang dihadapi atau mungkin akan dihadapi oleh organisasi. Analisis ini didasarkan agar dapat memaksimalkan kekuatan (strengths) dan peluang (opportunities), yang secara bersamaan dapat meminimalkan kelemahan (weaknesses) dan ancaman (threats).

Analisis SWOT terdiri atas empat komponen dasar, yaitu: (a) Strengths (S) adalah situasi atau kondisi kekuatan organisasi atau program pada saat ini; (b) weaknesses (W) adalah situasi atau kondisi kelemahan dari organisasi atau program pada saat ini; (c) opportunities (O) adalah situasi atau kondisi peluang yang berasal dari luar organisasi, dan threats (T) adalah situasi ancaman bagi organisasi yang datang dari luar organisasi dan dapat mengancam eksistensi organisasi pada masa depan.

Metode analisis SWOT dianggap sebagai metode analisis yang paling dasar, yang berguna untuk melihat suatu topik atau permasalahan dari empat sisi yang berbeda. Hasil analisis adalah menambah keuntungan dari peluang yang ada, dengan mengurangi kekurangan dan menghindari ancaman.

\section{Tujuan Analisis SWOT}

Menurut Bilung (2016:119) dengan analisis SWOT memungkinkan perusahaan untuk 
mengidentifikasi faktor-faktor yang mempengaruhi baik positif maupun negatif dari dalam dan dari luar perusahaan. Peran kunci dari SWOT adalah untuk membantu mengembangkan kesadaran penuh dari semua faktor yang dapat mempengaruhi perencanaan strategi dan pengambilan keputusan, tujuan yang dapat diterapkan pada hampir semua aspek industri.

Menurut Jogiyanto dalam Lukmandono (2015:44) tujuan dari analisis SWOT adalah sebagai berikut:

1. Mengidentifikasi kondisi internal dan eksternal yang terlibat sebagai input untuk merancang proses, sehingga proses yang dirancang dapat berjalan optimal, efektif, dan efisien.

2. Menganalisis suatu kondisi dimana akan dibuat sebuah rencana untuk melakukan sesuatu.

3. Mengetahui keuntungan yang dimiliki perusahaan.

4. Menganalisis prospek perusahaan untuk penjualan, keuntungan, dan pengembangan produk yang dihasilkan.

5. Menyiapkan perusahaan untuk siap dalam menghadapi permasalahan yang terjadi.

6. Menyiapkan untuk menghadapi adanya kemungkinan dalam perencanaan pengembangan di dalam perusahaan.

\section{Unsur-Unsur SWOT}

Menurut Dj. Rusmawati (2017:918) unsur-unsur SWOT meliputi:

\section{Kekuatan (Strengths)}

Unsur pertama dari SWOT adalah kekuatan (Strengths), yang dimaksud dengan kekuatan (Strengths) adalah semua potensi yang dimiliki perusahaan dalam mendukung proses pengembangan perusahaan, seperti kualitas sumber daya manusia, fasilitas-fasilitas perusahaan baik bagi SDM maupun bagi konsumen dan lain-lain. Yang dimaksud faktor-faktor kekuatan adalah antara lain kompetensi khusus yang terdapat dalam organisasi yang berakibat pada kepemilikan keunggulan komparatif oleh unit usaha dipasaran. Contoh: kekuatan pada sumber daya keuangan, citra positif, keunggulan kedudukan di pasar, dan kepercayaan bagi berbagai pihak yang berkepentingan atau yang berkaitan. 
2. Kelemahan (Weaknesses)

Adalah analisis kelemahan, dimana situasi dan kondisi yang merupakan kelemahan dari suatu perusahaan pada saat ini. Tepatnya terdapat kekurangan pada kondisi internal perusahaan, akibatnya kegiatan-kegiatan perusahaan belum bisa terlaksana secara maksimal. Misalnya: kekurangan dana, karyawan kurang kreatif dan malas, tidak adanya teknologi yang memadai dan sebagainya.

3. Peluang (Opportunities)

Adalah faktor-faktor lingkungan luar atau eksternal yang positif, secara sederhana dapat diartikan sebagai setiap situasi lingkungan yang yang menguntungkan bagi suatu perusahaan atau satuan bisnis.

4. Ancaman (Threats)

Ancaman yang dimaksud dalam analisis SWOT yang bisa terjadi di lapangan adalah:

a. Harga bahan baku yang fluktuatif

b. Masuknya pesaing baru di pasar.

c. Pertumbuhan pasar yang lambat.

d. Pelanggan yang memiliki kepekaan terhadap harga dapat pindah ke pesaing yang menawarkan harga murah.

e. Pesaing yang memiliki kapasitas yang lebih besar dan daya jangkau luas.

Faktor-faktor yang mempengaruhi SWOT

Menurut Purwanto dalam Dj. Rusmawati (2017:919) untuk menganalisis secara lebih dalam tentang SWOT, maka perlu dilihat faktor faktor eksternal dan internal sebagai bagian penting dalam analisis SWOT, yaitu:

1. Faktor Eksternal

Faktor eksternal ini bertujuan untuk mendapatkan faktor-faktor yang menjadi peluang dan ancaman organisasi ini.

2. Faktor Internal 
Faktor internal ini bertujuan untuk mendapatkan faktor-faktor yang menjadi kekuatan dan kelemahan organisasi ini.

\section{Matriks SWOT}

Dalam Rangkuti (2017:83-84) Alat yang dipakai untuk menyusun faktor-faktor strategis perusahaan adalah matrik SWOT. Matriks ini dapat mengambarkan secara jelas bagaimana peluang dan ancaman eksternal yang dihadapi perusahaan dapat disesuaikan dengan kekuatan dan kelemahan yang dimilikinya. Matriks ini dapat menghasilkan empat set kemungkinan alternatif strategis.

Tabel 1. Matriks SWOT

\begin{tabular}{|c|c|c|}
\hline$I F A S$ & $\begin{array}{l}\text { STRENGTHS } \\
\text { (S) }\end{array}$ & $\begin{array}{l}\text { WEAKNESSES } \\
\text { (W) }\end{array}$ \\
\hline$E F A S$ & $\begin{array}{l}\text { Tentukan 5- } 10 \text { faktor } \\
-\quad \text { faktor kekuatan } \\
\text { internal }\end{array}$ & $\begin{array}{l}\text { Tentukan 5- } 10 \\
\text { kelemahan } \\
\text { internal }\end{array}$ \\
\hline $\begin{array}{l}\text { OPPORTUNITIES } \\
\text { (O) }\end{array}$ & STRATEGI SO & STRATEGI WO \\
\hline $\begin{array}{l}\text { Tentukan 5-10 faktor } \\
\text { peluang eksternal }\end{array}$ & $\begin{array}{l}\text { Ciptakan strategi yang } \\
\text { menggunakan kekuatan } \\
\text { untuk memanfaatkan } \\
\text { peluang }\end{array}$ & $\begin{array}{l}\text { Ciptakan strategi yang } \\
\text { meminimalkan } \\
\text { kelemahan untuk } \\
\text { memanfaatkan } \\
\text { peluang }\end{array}$ \\
\hline
\end{tabular}




\begin{tabular}{|c|c|c|}
\hline THREATS $(T)$ & STRATEGI ST & STRATEGI WT \\
\hline $\begin{array}{l}\text { Tentukan } \quad 5-10 \\
\text { faktor ancaman } \\
\text { eksternal }\end{array}$ & $\begin{array}{l}\text { Ciptakan strategi yang } \\
\text { menggunakan kekuatan } \\
\text { untuk mengatasi } \\
\text { ancaman }\end{array}$ & $\begin{array}{l}\text { Ciptakan strategi } \\
\text { yang meminimalkan } \\
\text { kelemahan dan } \\
\text { menghindari } \\
\text { ancaman }\end{array}$ \\
\hline
\end{tabular}

Sumber: Teknik Membedah Kasus Bisnis Analisis SWOT (2017:26)

\section{a. Strategi SO (Strength-Opportunities)}

Strategi ini dibuat berdasarkan jalan pikiran perusahaan, yaitu dengan memanfaatkan seluruh kekuatan untuk merebut dan memanfaatkan peluang yang sebesar-besarnya.

\section{b. Strategi ST (Strenghts-Threats)}

Ini adalah strategi dalam menggunakan kekuatan yang dimiliki perusahaan untuk mengatasi ancaman.

\section{c. Strategi WO (Weknesses- Opportunities)}

Strategi ini diterapkan berdasarkan pemanfaatan peluang yang ada dengan cara meminimalkan kelemahan yang ada.

\section{d. Strategi WT (Weaknesses- Threats)}

Strategi ini berdasarkan pada kegiatan yang bersifat defensive dan berusaha meminimalkan kelemahan yang ada serta menghindari ancaman.

\section{Matriks Internal - Eksternal (IE)}

Menurut Rangkuti dalam Maulana (2017:51) Matriks IE (Internal- External) merupakan pemetaan skor matriks EFAS dan IFAS yang telah dihasilkan dari tahap input (input stage) dan memposisikan perusahaan dalam tampilan sembilan sel. Matriks IE didasarkan 
pada dua dimensi kunci yaitu total skor pembobotan IFAS pada sumbu horizontal dan total skor pembobotan EFAS pada sumbu vertikal. Pada sumbu horizontal dari matriks IE, total skor bobot dari 1,0 hingga 1,99 menunjukkan posisi internal lemah; nilai dari 2,0 hingga 2,99 adalah sedang; dan nilai dari 3,0 hingga 4,0 adalah posisi internal yang kuat. Pada sumbu vertikal dari matriks IE, total skor bobot dari 1,0 hingga 1,99 menunjukkan posisi eksternal yang lemah; nilai dari 2,0 hingga 2,99 menunjukkan pengaruh eksternal sedang; dan nilai dari3,0 hingga 4,0 adalah pengaruh eksternal yang kuat.

Menurut David dalam Maulana (2016:52), konsep matriks IE dapat dibagi menjadi tiga daerah utama yang memiliki implikasi strategi yang berbeda-beda. Pertama, divisi yang masuk dalam sel I, II, dan IV dapat digambarkan sebagai tumbuh dan membangun (grow and build). Strategi yang intensif (penetrasi pasar, pengembangan pasar, dan pengembangan produk) atau strategi integratif (integrasi ke belakang, integrasi ke depan, dan integrasi horizontal) dapat menjadi strategi yang paling sesuai untuk divisi dalam sel ini. Kedua, divisi yang masuk dalam sel III, V, atau VII dapat dikelola dengan cara terbaik menggunakan strategi menjaga dan mempertahankan (hold and maintain). Strategi yang tepat untuk tipe ini adalah penetrasi pasar dan pengembangan produk. Ketiga, rekomendasi yang umum diberikan untuk divisi yang masuk dalam sel VI, VIII, dan IX adalah panen atau divestasi divestasi (harvest or divestiture)

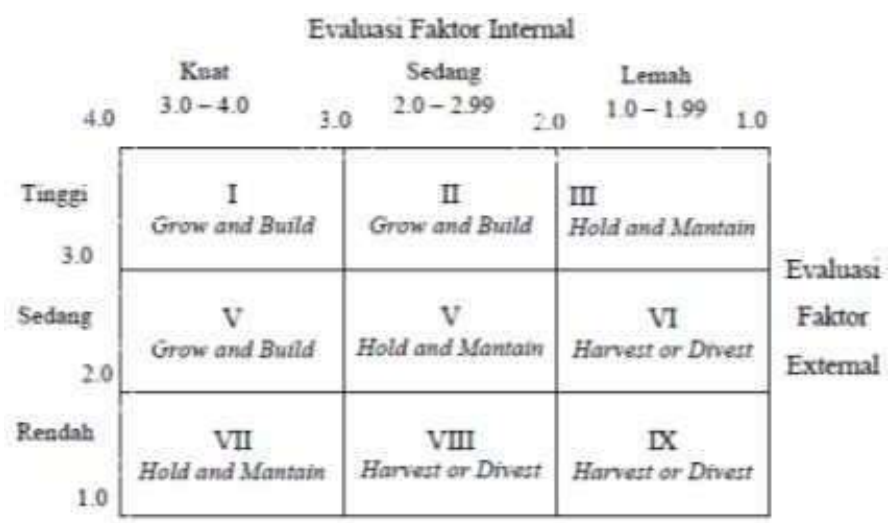

Gambar 1. : Matriks Internal Eksternal

\section{METODE PENULISAN}

Jenis penelitian yang dilakukan oleh peneliti adalah jenis penelitian dengan metode 
kualitatif. Menurut Sugiyono (2014, p.8), penelitian kualitatif sering disebut metode penelitian naturalistik karena penelitiannya dilakukan pada kondisi alamiah (natural setting). Metode kualitatif digunakan untuk mendapatkan data yang mendalam, suatudata yang mengandung makna. Makna adalah data yang sebenarnya, data yang pasti yang merupakan suatu nilai dibalik data yang tampak. Oleh karena itu dalam penelitian kualitatif tidak menekankan pada generalisasi, tetapi lebih menekankan pada makna.

\section{PEMBAHASAN}

\section{1) Strategi Pengembangan SDM berpengaruh terhadap SWOT}

Strategi pengembangan SDM merupakan suatu perencanaan mengenai cara bagaimana kualitas SDM mampu berkembang ke arah yang lebih baik dan meningkat kemampuan kerjanya. Serta memiliki loyalitas yang baik terhadap perusahaan. Pengembangan SDM sangat dibutuhkan untuk kelangsungan sebuah perusahaan agar dapat berkembang secara lebih dinamis. Sebab SDM merupakan unsur yang paling penting di dalam sebuah perusahaan. Analisis SWOT dapat digunakan untuk perencanaan strategi talent acquisition yang efektif dalam meningkatkan kualitas SDM perusahaan.

\section{2) Strategi Bisnis berpengaruh terhadap SWOT}

Strategi bisnis merupakan rencana dan tindakan jangka panjang yang dirancang untuk mencapai tujuan tertentu atau serangkaian tujuan atau sasaran. Strategi adalah rencana permainan manajemen untuk memperkuat kinerja perusahaan. Ini menyatakan bagaimana bisnis harus dilakukan untuk mencapai tujuan yang diinginkan. Meskipun Analisa SWOT dapat membantu pelaku bisnis dalam menyadari elemen-elemen penting dalam pengembangan bisnis, namun upaya pengembangan bisnis tidak berhenti di tahap itu. Perlu adanya upaya yang tepat dalam menerapkan Analisa yang telah dibuat. Langkah selanjutnya dari pembuatan Analisa SWOT adalah menyusun strategi sebenarnya berdasarkan Analisa tersebut. Mulai dengan membuat produk dengan nilai yang tepat sesuai Analisa SWOT. Sejalan dengan itu, siapkan rencana kerja, alokasi sumber daya, serta tentukan target yang ingin dicapai.

\section{3) Strategi MSDM berpengaruh terhadap SWOT}

Strategi Manajemen sumber daya manusia merupakan suatu proses menangani berbagai masalah pada ruang lingkup karyawan, pegawai, buruh, manajer dan tenaga kerja lainnya untuk dapat menunjang aktifitas organisasi atau perusahaan demi mencapai tujuan yang telah 
disepakati bersama. Setiap organisasi tidak lepas dari manajemen sumber daya manusia (MSDM) Strategik karena MSDM Strategik dapat menjadi sebuah inovasi organisasi untuk mencapai tujuan yang diinginkan organisasi. Dengan menggabungkan Strategi MSDM pada SWOT maka SDM yang di hasilkan lebih berkualitas.

\section{DAFTAR PUSTAKA}

Jogiyanto, H.M., 2005, Analisa dan Desain Sistem Informasi: Pendekatan Terstruktur Teori dan Praktik Aplikasi Bisnis, ANDI, Yogyakarta.

Rangkuti, Freddy, 2013. Analisis SWOT. PT Gramedia Pustaka. Jakarta.

Mahmud dan Anomsari, Analisis Pengaruh Orientasi Kewirausahaan, Kemampuan Manajemen, dan Strategi Bisnis Dalam Peningkatan Kinerja Perusahaan (Studi Pada Usaha Kecil Menengah di Kawasan Usaha Barito Semarang), Seminar Nasional Teknologi Informasi \& Komunikasi Terapan 2011 (Semantik 2011), 2011, hal. 3.

Penentuan Prioritas Strategi Pariwisata Dengan Menggunakan Metode Quantitative Strategic Planning Matrix, Maulana (2016:52).

Sugiyono. (2011). Metode Penelitian Kuantitatif, Kualitatif dan R\&D. Bandung: Afabeta. Sugiyono. (2014). Metode penelitian kuantitatif kualitatif dan R\&D, Cet. Ke 20, Bandung: Alfabeta. 